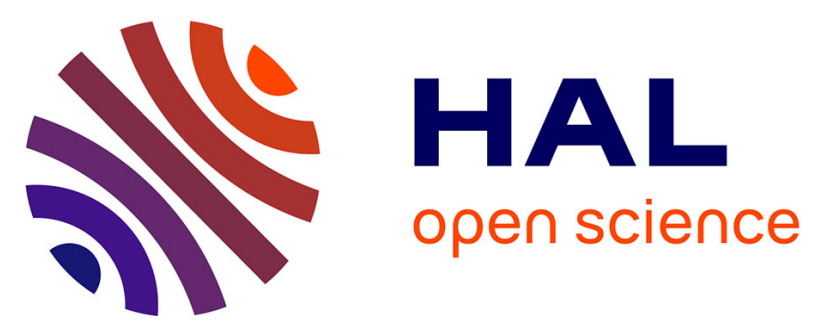

\title{
Effect of 3 Preservation Methods (Freezing, Cryopreservation, and Freezing plus Irradiation) on Human Menisci Ultrastructure An Ex Vivo Comparative Study With Fresh Tissue as a Gold Standard
} Christophe Jacquet, Roger Erivan, Jean-Noël Argenson, Sebastien Parratte, Matthieu Ollivier

\section{To cite this version:}

Christophe Jacquet, Roger Erivan, Jean-Noël Argenson, Sebastien Parratte, Matthieu Ollivier. Effect of 3 Preservation Methods (Freezing, Cryopreservation, and Freezing plus Irradiation) on Human Menisci Ultrastructure An Ex Vivo Comparative Study With Fresh Tissue as a Gold Standard. The American Journal of Sports Medicine, 2018, 46 (12), pp.2899-2904. 10.1177/0363546518790504 . hal-01960535

\section{HAL Id: hal-01960535 \\ https://hal.science/hal-01960535}

Submitted on 17 Apr 2019

HAL is a multi-disciplinary open access archive for the deposit and dissemination of scientific research documents, whether they are published or not. The documents may come from teaching and research institutions in France or abroad, or from public or private research centers.
L'archive ouverte pluridisciplinaire HAL, est destinée au dépôt et à la diffusion de documents scientifiques de niveau recherche, publiés ou non, émanant des établissements d'enseignement et de recherche français ou étrangers, des laboratoires publics ou privés. 


\title{
Effect of 3 Preservation Methods (Freezing, Cryopreservation, and Freezing 1 Irradiation) on Human Menisci Ultrastructure
}

\section{An Ex Vivo Comparative Study With Fresh Tissue as a Gold Standard}

\author{
Christophe Jacquet, ${ }^{* y} \mathrm{MD}$, Roger Erivan, ${ }^{\mathrm{z}} \mathrm{MD}$, Jean-Noël Argenson, ${ }^{\mathrm{*}} \mathrm{MD}, \mathrm{PhD}$, \\ Sebastien Parratte, ${ }^{* y} \mathrm{MD}, \mathrm{PhD}$, and Matthieu Ollivier, ${ }^{* \mathrm{y} s} \mathrm{MD}, \mathrm{PhD}$ \\ Investigation performed at the Institute of Movement and Locomotion, \\ Department of Orthopedic Surgery and Traumatology, St Marguerite Hospital, Marseille, France
}

Background: Three main meniscus preservation methods have been advocated: freezing $\left(-80^{\circ} \mathrm{C}\right)$, freezing with gamma irradiation $\left(-80^{\circ} \mathrm{C} 125 \mathrm{kGy}\right)$, and cryopreservation $\left(-140^{\circ} \mathrm{C}\right)$.

Hypothesis: All preservation methods will result in structural and architectural properties similar to those of fresh meniscus, defined as the gold standard.

Study Design: Controlled laboratory study.

Methods: Five human intact menisci were collected from 5 patients undergoing total knee arthroplasty. The inclusion criteria were patients $\backslash 70$ years old with primary unilateral (medial) femorotibial knee osteoarthritis and without surgical or traumatic history on the operated knee. Four cubes $\left(9 \mathrm{~mm}^{3}\right)$ were cut inside of the white, or avascular, area of each specimen's middle horn and divided into 4 groups: "fresh" control, frozen $\left(-80^{\circ} \mathrm{C}\right)$, cryopreserved $\left(-140^{\circ} \mathrm{C}\right)$, and frozen 1 irradiated $\left(-80^{\circ} \mathrm{C} 125 \mathrm{kGy}\right)$. Specimens of the control group were evaluated at day 1 , and specimens from the frozen, cryopreserved, and frozen 1 irradiated groups were evaluated after 1 month of storage. Evaluation was performed with electron microscopy according a validated protocol to analyze (1) mean diameters of the collagen fibers in longitudinal and transverse sections in 5 points per section and (2) validated architectural scores.

Results: No significant difference was found between the control and cryopreserved groups regarding mean transverse and longitudinal diameters (transverse: $95.39615 .87 \mathrm{~nm}$ vs $99.62619 .23 \mathrm{~nm}, P=.1$; longitudinal: $96.31613 .96 \mathrm{~nm}$ vs 94.57616 .42 $\mathrm{nm}, P=.1$ ). Significant differences were found between the control and frozen groups (transverse: $95.39615 .87 \mathrm{~nm}$ vs 70.206 $13.94 \mathrm{~nm}, P \backslash .001$; longitudinal: $96.31613 .96 \mathrm{nmvs} 71.28610 .64 \mathrm{~nm}, P \backslash .001$ ) and the control and frozen 1 irradiated groups (transverse: $95.39615 .87 \mathrm{~nm}$ vs $63.1615 .57 \mathrm{~nm}, P \backslash .001$; longitudinal: $96.31613 .96 \mathrm{~nm}$ vs $60.9614 .8 \mathrm{~nm}, P \backslash$ $.001)$. Regarding architectural score calculation, there were significant differences between the control and frozen groups (4.5 61.3 vs $2.361 .4, P=.02$ ) and the control and frozen 1 irradiated groups (4.5 61.3 vs $1.460 .9, P=.02$ ).

Conclusion: Cryopreservation is the only method that preserves fresh meniscus architectural specificities. Freezing and freezing 1 irradiation methods modify histologic properties of meniscal allograft. Irradiation deeply alters diameters and the organization of collagen fibers, and this method should be used with caution to preserve and sterilize meniscus tissue.

Clinical Relevance: The results of our study exhibited detrimental effects of simple freezing and freezing 1 irradiation on the collagen network of sample meniscus. If those effects occur in menisci prepared for allograft procedures, important differences could appear on the basis of the preservation procedure in terms of the graft's mechanical properties and, thus, the patient's outcomes.

Keywords: meniscus allograft; irradiation; cryopreservation; freezing; histologic; collagen

The American Journal of Sports Medicine $1-6$

DOI: $10.1177 / 0363546518790504$

(C) 2018 The Author(s)
The long-term deleterious effects of total meniscectomy include pain, potential instability, and osteoarthritis. ${ }^{10,11,14}$ To treat these painful issues, menisci allografts are advocated 
to restore knee joint mechanics and potentially slow the onset of osteoarthritis. ${ }^{15}$ Verdonk et $\mathrm{al}^{19}$ described midterm results showing a significant improvement in patients' pain associated with 5-year allograft survival - 85\%. ${ }^{18,19,21}$ As those interesting results imply a meniscal graft equivalent to the native fibrocartilage, graft preservation methods play a vital role in the clinical and biological success of meniscal allograft techniques. Three main menisci preservation methods were advocated: freezing, freezing with gamma irradiation, and cryopreservation. ${ }^{17}$ Simple freezing brings the material to $280^{\circ} \mathrm{C}$, but deep modification of the collagen network and global architecture was reported with this preservation.,9 Freezing associated with irradiation allows a deep sterilization of the graft but also compromises allograft microarchitectural and biomechanical properties. ${ }^{5,17}$ Cryopreservation techniques require cryoprotectants (dimethylsulfoxide) and bring the tissue to $2145^{\circ} \mathrm{C}$. Gelber et $\mathrm{al}^{7}$ demonstrated that cryopreservation was superior to freezing to maintain the meniscus ultrastructure during the storage process. To date, studies investigating human meniscus preservation had 2 main limitations: first, they did not compare preservation processes with the same meniscus sample; second, conserved tissues are not compared with fresh meniscus samples. As meniscus ultrastructure depends on various demographic and pathologic confounding factors, comparing potential detrimental effects of various conservation processes should be performed on "identical" tissue samples.1,3,8,12 Therefore, we aimed to analyze and compare 3 preservation processes with a "fresh tissue" control group using samples harvested from the same human meniscus. We hypothesized that all preservation methods would result in structural and architectural properties similar to those of fresh meniscus, defined as the gold standard. We aimed to estimate the effects of these methods on meniscus ultrastructure by using electronic microscopy to compare collagen fiber diameters in longitudinal and transverse sections and by calculating a validated architectural score per sample. ${ }^{6,7}$

\section{METHODS}

After local review board approval, 5 human lateral menisci were collected from patients who had total knee arthroplasty between September and October 2017. All patients signed an informed consent form before their inclusion in our study. Inclusion criteria were as follows: patient aged $\backslash 70$ years undergoing total knee arthroplasty because of isolated internal femorotibial arthritis or femoropatellar and internal femorotibial joint degeneration (but with an external femorotibial compartment graded Kellgren and Lawrence $\backslash 2)^{13}$ and no surgery, trauma, or developmental disease of the operated knee. Table 1 summarizes patients' characteristics.
TABLE 1

Patients' Demographics ${ }^{a}$

\begin{tabular}{lccccc}
\hline Patient & Age, y & Sex & Weight, kg & Size, cm & BMI, kg.m ${ }^{-2}$ \\
\hline 1 & 61 & M & 76 & 181 & 22.6 \\
2 & 67 & M & 82 & 184 & 24.2 \\
3 & 62 & F & 67 & 172 & 22.1 \\
4 & 60 & F & 60 & 162 & 22.9 \\
5 & 69 & M & 77 & 178 & 24.3 \\
\hline
\end{tabular}

${ }^{a} \mathrm{BMI}$, body mass index.

\section{Sample Creation}

The anterior and posterior horns were sectioned to retain only the median horn of the meniscus. Four cubes $\left(9 \mathrm{~mm}^{3}\right)$ were cut inside of the white, or avascular, area of each specimen and divided into 4 groups: "fresh" control, freezing, cryopreserved, and freezing 1 irradiation. Histologic fixation of the control specimens was performed directly in the operating theater under a hood, which consisted of the following steps based on a previously validated protocol:

1. Five-minute rinsing with $0.1 \mathrm{M}$ cacodylate buffer.

2. Fixation in a solution of $2.5 \%$ glutaraldehyde in cacodylate buffer for 1 hour.

3. Rinsing 3 times for 10 minutes with $0.1 \mathrm{M}$ cacodylate buffer.

4. Postfixation with a solution of $2 \%$ osmium tetroxide in $0.1 \mathrm{M}$ cacodylate buffer for 30 minutes.

5. Rinsing 3 times for 15 minutes with $0.1 \mathrm{M}$ cacodylate buffer.

6. Progressive dehydration of samples ranging from $50 \%$ to $100 \%$ ethanol before inclusion in Spurr. ${ }^{20}$

7. Resin fixation for transmission electron microscopy

Control specimens were analyzed immediately after those steps in a delay $\backslash 6$ hours. The other 3 fragments were placed in physiologic saline in a cryokit and kept at $8^{\circ} \mathrm{C}$ until their transport to our local tissue bank (Etablissement Franxcais du Sang) ( $\backslash 6$ hours). The 3 samples were then prepared with the following steps: (1) graft reception in clean room (controlled atmosphere zone), (2) decontamination of the graft with an antibiotic solution (rifampicin 1 thiamphenicol), (3) rinsing with $0.1 \mathrm{M}$ cacodylate buffer for 5 minutes, and (4) bacteriologic sampling. Then, the 3 conservation methods were applied (1 sample for each). For the cryopreservation group, cryoprotective solution (10\% of DMSO 1 SCOT 30) was added, and the bag was vacuumed to extract the residual air and the temperature progressively decreased (staring at $24^{\circ} \mathrm{C}$ and then decreasing at $22^{\circ} \mathrm{C}$ per minute to $240^{\circ} \mathrm{C}$ and then $25^{\circ} \mathrm{C}$ per minute to $2140^{\circ} \mathrm{C}$ ). Samples were stored in a nitrogen tank in vapor phase at $2145^{\circ} \mathrm{C}$. For the freezing group, a simple freezing

\footnotetext{
${ }^{\S}$ Address correspondence to Matthieu Ollivier, MD, PhD, Institute of Movement and Locomotion, Department of Orthopedics and Traumatology, St Marguerite Hospital, 270 Boulevard Sainte Marguerite, BP 2913274 Marseille, France (email: ollivier.matthieu@yahoo.fr).

*Aix-Marseille Universite, CNRS, ISM UMR 7287, Marseille, France.

YInstitute of Movement and Locomotion, Department of Orthopedics and Traumatology, St Marguerite Hospital, Marseille, France.

${ }^{z}$ Universite Clermont Auvergne, CHU Clermont-Ferrand, CNRS, SIGMA Clermont, ICCF, Clermont-Ferrand, France.

One or more of the authors has declared the following potential conflict of interest or source of funding: M.O. is a consultant for Stryker and Nex-clip. J.N.A. is a consultant for Zimmer. S.P. is a consultant for Zimmer, Arthrex, and Nex-clip.
} 


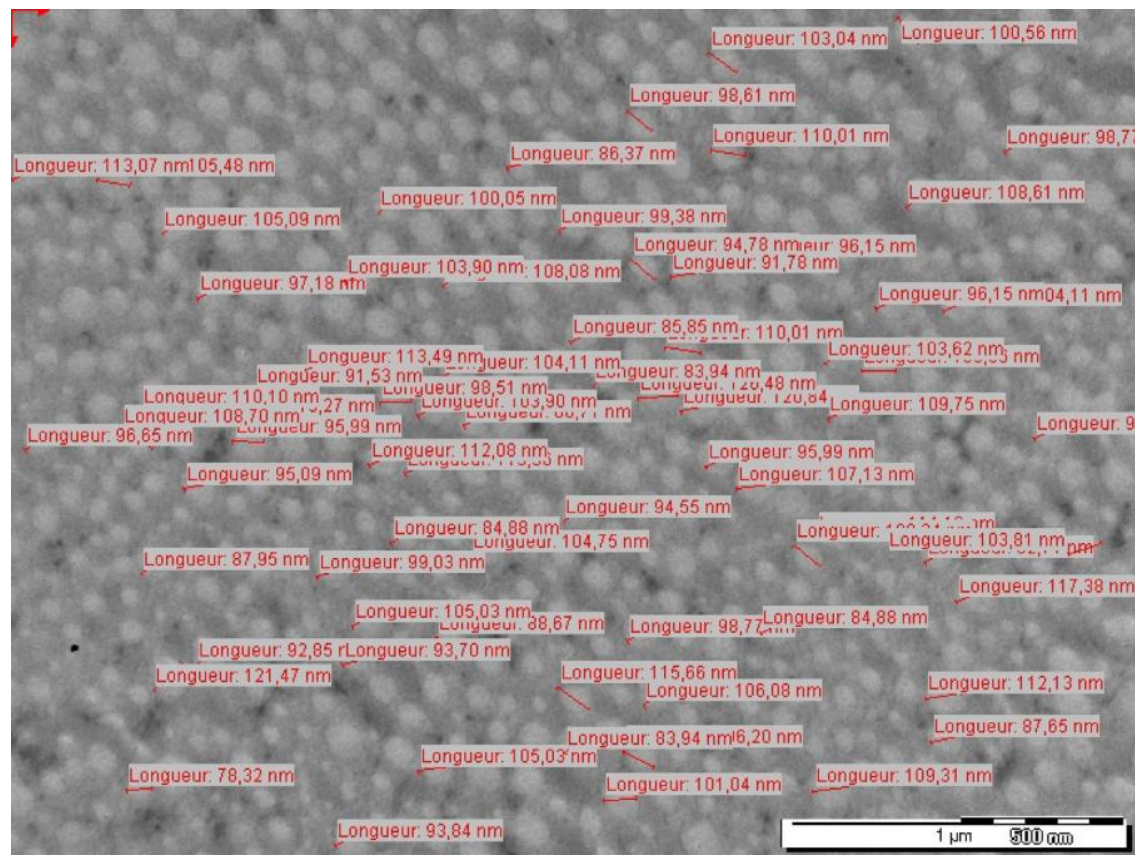

Figure 1. Example of longitudinal diameter measurement (cryopreserved sample diameter estimated on a picture at 40,0003 magnification).

process was used by progressively decreasing the temperature (staring at $24^{\circ} \mathrm{C}$ and then decreasing at $22^{\circ} \mathrm{C}_{\text {per min- }}^{-}$ ute to $240^{\circ} \mathrm{C}$ and then $25^{\circ} \mathrm{C}$ per minute to $280^{\circ} \mathrm{C}$ ). For the freezing 1 irradiation group, a simple freezing process with a progressive decrease in temperature was performed (starting at $24^{\circ} \mathrm{C}$ and then decreasing at $22^{\circ} \mathrm{C}$ per minute to $240^{\circ} \mathrm{C}$ and then $25^{\circ} \mathrm{C}$ per minute to $280^{\circ} \mathrm{C}$ ). The grafts were then transported in a dry ice-controlled container (stored at $280^{\circ} \mathrm{C}$ ) to be irradiated by gamma ray by IONISOS. The doses received ranged between 23.9 and $26.5 \mathrm{kGy}$ (2.4-2.6 Mrad). After this treatment, the samples were again stored at $280^{\circ} \mathrm{C}$ until analysis.

After 1 month, the samples were transported to the electronic microscopy laboratory to be analyzed. The fixing steps (steps 1-7) were the same as those described for the control group. For all samples, ultrafine $60-\mathrm{nm}$ sections were made with an Ultracut ultramicrotome (ReichertJung); contrast of the sections was made with uranyl acetate and lead citrate. Ultrastructure pictures were obtained with a transmission electron microscope (JEM 1400; JEOL) at $80 \mathrm{kV}$ with a Megaview III camera and iTEM Five software (SIS Imaging). For each sample, we took 10 pictures with a magnification of 60003 and 40,0003. The longitudinal (Figure 1) and transverse diameters of the collagen fibers were measured at 70 points on a picture taken at 40,0003 magnification. The collagen meniscal architecture scoring system was calculated for each sample on 5 pictures with 60003 magnification (Table 2). ${ }^{7}$

\section{Statistics}

Before the initiation of the study, a sample analysis estimated that 5 samples for each group was necessary to be
TABLE 2

Collagen Meniscal Architecture Scoring System

\begin{tabular}{lccc}
\hline & 0 Point & 1 Point & 2 Points \\
\hline Disrupt/periodicity & Mild & Moderate & Severe \\
Intrafibrillary edema & No & Yes & - \\
Packing & High density & Intermediate Low density \\
Banding & Yes & No & - \\
Fibril size variability & Low & High & - \\
\hline
\end{tabular}

powered to distinguish D $20610 \mathrm{~nm}$ regarding collagen transverse or longitudinal diameters. ${ }^{4,5,7}$

Patient characteristics were expressed with the appropriate descriptive statistics for the type of variables. Descriptive statistics included mean with SD or median with interquartile range as appropriate for continuous variables. The intraclass correlation coefficient with $95 \%$ CIs was calculated to assess intra- and interobserver reproducibility for the transverse and longitudinal diameter values. Student $t$ tests were used to compare the distribution of continuous parameters between groups (or the Mann-Whitney test when the data were not normally distributed or when the homoscedasticity assumption was rejected). All reported $P$ values were 2 -sided, with a significance threshold of .05. Statistical analyses were performed with SPSS/JMP software (v 13; Microsoft).

\section{RESULTS}

\section{Transverse Diameter}

No significant difference was found between the control and cryopreserved groups regarding mean transverse 
TABLE 3

Collagen Fiber Transverse Diameter Comparison Among Groups

\begin{tabular}{|c|c|c|c|c|}
\hline \multicolumn{2}{|c|}{ Group Comparison } & \multirow{2}{*}{$\frac{\text { Mean Difference, } \mathrm{nm}}{4.22}$} & \multirow{2}{*}{$\frac{95 \% \mathrm{CI}, \mathrm{nm}}{1.36-7.08}$} & \multirow{2}{*}{$\frac{P \text { Value }}{.1}$} \\
\hline Control & Cryopreserved & & & \\
\hline Control & Irradiated & 32.27 & $29.55-34.99$ & $\backslash .001$ \\
\hline Control & Frozen & 25.191 & $22.61-27.77$ & $\backslash .001$ \\
\hline Cryopreserved & Frozen & 29.413 & $26.5-32.2$ & $\backslash .001$ \\
\hline Cryopreserved & Irradiated & 36.4 & $33.34-39.65$ & $\backslash .001$ \\
\hline Frozen & Irradiated & 7.08 & $4.64-9.52$ & .023 \\
\hline
\end{tabular}

TABLE 4

Collagen Fiber Longitudinal Diameter Comparison Among Groups

\begin{tabular}{|c|c|c|c|c|}
\hline \multicolumn{2}{|c|}{ Group Comparison } & \multirow{2}{*}{$\frac{\text { Mean Difference, } \mathrm{nm}}{1.738}$} & \multirow{2}{*}{$\frac{95 \% \mathrm{CI}, \mathrm{nm}}{0.55-4.03}$} & \multirow{2}{*}{$\frac{P \text { Value }}{.1}$} \\
\hline Control & Cryopreserved & & & \\
\hline Control & Irradiated & 35.39 & $32.79-37.98$ & $\backslash .001$ \\
\hline Control & Frozen & 25.02 & $22.86-27.19$ & $\backslash .001$ \\
\hline Cryopreserved & Frozen & 23.29 & $20.87-25.70$ & $\backslash .001$ \\
\hline Cryopreserved & Irradiated & 33.65 & $30.99-36 . .31$ & $\backslash .001$ \\
\hline Frozen & Irradiated & 10.36 & $8.24-12.49$ & .011 \\
\hline
\end{tabular}

diameter (95.396 $15.87 \mathrm{~nm}$ vs $99.62619 .23 \mathrm{~nm}, P=.1$ ). There was a significant difference between the control and frozen groups $(95.39615 .87 \mathrm{~nm}$ vs $70.20613 .94 \mathrm{~nm}, P \backslash$ .001) and between the control and frozen 1 irradiated groups (95.39 $615.87 \mathrm{~nm}$ vs $63.1615 .57 \mathrm{~nm}, P \backslash .001$ ) (Table 3).

The mean difference between the frozen and frozen 1 irradiated groups was also significant: D $7.1 \mathrm{~nm}$ (95\% CI, 4.6-9.5 nm; $P \backslash .023)$.

\section{Longitudinal Diameter}

We found no significant difference in mean longitudinal diameter between the control and cryopreserved groups (96.36 $14 \mathrm{~nm}$ vs $94.6616 .4 \mathrm{~nm}, P=.1)$. There was a significant difference in mean longitudinal diameter between the control and frozen groups $(96.3614 \mathrm{~nm}$ vs $71.3610 .6 \mathrm{~nm}$, $P \backslash .001)$ as well as the frozen 1 irradiated groups (96.36 $14 \mathrm{~nm}$ vs $60.9614 .8 \mathrm{~nm}, P \backslash .001$ ) (Table 4 ).

The mean difference between the frozen and frozen 1 irradiated groups was also significant: D $10.6 \mathrm{~nm}(95 \%$ CI, 8.2-12.5 nm; $P \backslash .011)$.

\section{Collagen Meniscal Scoring System}

The mean values of the collagen meniscal architecture scoring system are summarized in Table 5. No difference was found between the control and cryopreserved groups (4.5 61.3 vs 4.361 .6 points, $P=.9$ ). There were significant differences between the control and frozen groups (4.56 1.3 vs 2.361 .4 points, $P=.02$ ) and between the control and frozen 1 irradiated groups $(4.561 .3 \mathrm{vs} 1.460 .9$, $P=.02)$.

\section{DISCUSSION}

The main finding of the current study was that cryopreservation preserves meniscus histologic ultrastructure, unlike simple freezing or freezing 1 irradiation. We rejected our hypothesis that all preservation methods will result in structural and architectural properties similar to those of fresh meniscus. Cryopreservation does not entail a significant modification in terms of collagen fiber diameter or architectural organization as compared with fresh tissue. We did find, however, significant differences regarding those 2 measurements when we compared freezing and freezing 1 irradiation processes with fresh tissue or cryopreserved samples. Irradiation was the more detrimental process in terms of tissue preservation, as all of our measurements were inferior to those taken for fresh tissue, cryopreservation, and freezing samples.

Our study is limited in that our patients are older than usual donors $^{2}$ (mean age: 63.8 years in our study vs 53.5 in the register). Because of this, menisci evaluated during our analyses might have been altered by aging and degeneration processes. We tried to avoid limitations related to this methodological bias by studying nonarthritic joints (lateral compartment) from subjects having only medial femorotibial degeneration. Moreover, our direct comparative design allowed us to think that potential degenerative changes would have similarly affected our evaluation of the 3 preservation methods, since the compared samples were created from the same meniscus. Our relatively short storage period before the analysis could also be considered a limitation. We supposed that most of the ultrastructure alteration related to the preservation method occurred during the decreasing-of-temperature steps, including direct chemical effects, ice formation, and dehydration, as described by Pegg. ${ }^{16}$ Our evaluation method involved manual measurement of 
TABLE 5

Collagen Meniscal Architecture Scoring Comparison Between Preserved and Control Samples

\begin{tabular}{lcc}
\hline Group & Score, Mean 6 SD & $P$ Value \\
\hline Control vs & 4.561 .3 & - \\
Cryopreservation & 4.361 .6 & .9 \\
Frozen & 2.361 .4 & .02 \\
Irradiation & 1.460 .9 & .02 \\
\hline
\end{tabular}

collagen fiber diameters; as such, 1 senior technician trained in transmission electron microscopy carried out the entire collection of data and was blinded regarding the preservation process of the specimens. The measurements were always made at the same magnification $(40,0003)$ and at 70 random points of the picture, with consideration to only the most circular fibers for the transverse diameter and the most linear for the longitudinal diameter. Our protocol did not aim to investigate cell viability. It was impossible for us to perform both ultrastructure analysis and flow cytometric cell counts on the same sample. Gelber et al ${ }^{7}$ were the first to demonstrate that cell survival was possible in cryopreserved samples, but in a study of 15 meniscal goat allografts, Fabbriciani et $\mathrm{al}^{4}$ showed that even if cryopreservation made it possible to maintain partial cell viability in the tissue, the morphologic and biochemical characteristics of the graft were not improved. Finally, our sample size might seem low, but the numbers of specimens included was decided before the initiation of the study to compare groups upon collagen thickness evaluation.

Despite these limitations, our study is the first to directly compare the influence of preservation processes on 4 samples prepared from the same meniscus, permitting us to assert that the differences observed are mostly related to preservation methods and their specificities more than demographic confounding factors.

We used the collagen meniscal scoring system by Gelber et $\mathrm{al}^{6,7}$ to compare our results with the existing literature. Gelber et $\mathrm{al}^{6,7}$ advocated the superiority of cryopreservation on meniscus ultrastructure as compared with freezing, with 2 studies corroborating our results, even if they did not use a control group. In another study, Vangsness et $\mathrm{al}^{17}$ demonstrated that the use of gamma irradiation caused clear alteration of musculoskeletal tissues mechanical properties.

Bone sample load-to-failure behavior was significantly lower when exposed to $-3 \mathrm{Mrad}$ of irradiation. ${ }^{17}$ Fideler et $\mathrm{al}^{5}$ determined that -2 Mrad of irradiation of bonepatellar tendon-bone allografts adversely affected 4 of the 7 structural properties that were analyzed. Thus, they found that all structural parameters were deeply affected at irradiation levels of 3.0 and $4.0 \mathrm{Mrad}$. This conclusion is supported by our data: we found the highest rate of collagen disorganization for samples exposed to

2.5 Mrad (25 kGy: freezing 1 irradiation group). Advantages in terms of sterilization allowed by gamma irradiation should be balanced with those deep architectural and potentially mechanical consequences.

With regard to the meniscus, Lewis et al ${ }^{15}$ studied 7 human menisci and demonstrated that samples that underwent a single freeze-thaw cycle had a significantly higher Young modulus than did those undergoing multiple freeze-thaw cycles (Young modulus: $1.2310^{7}$ for 1 cycle vs $8.5310^{6}$ for multiple cycles).

Our histologic results must be confirmed by mechanical trials to better understand potential consequences of ultrastructure alteration on meniscal graft mechanical properties. In the same manner, only in vivo studies will be able to assess the real clinical relevance of our ex vivo conclusion.

\section{CONCLUSION}

Cryopreservation is the only method that preserves fresh meniscus architectural specificities. Freezing and freezing 1 irradiation methods modify histologic properties of meniscal allograft. Irradiation deeply alters diameters and organization of collagen fibers, and this method should be used with caution to preserve and sterilize menisci tissue.

\section{ACKNOWLEDGMENT}

The authors thank Alexandre Altie for his support during electron microscopy analysis.

\section{REFERENCES}

1. Choi Y-H, Seo Y-J, Ha JM, Jung KH, Kim J, Song SY. Collagenous ultrastructure of the discoid meniscus: a transmission electron microscopy study. Am J Sports Med. 201 7;45(3):598-603.

2. Cohen J, Bistritz Y, Ashkenazi T. Deceased organ donor characteristics and organ utilization in Israel, 2004-2013. Isr Med Assoc J. 2015;17(6):365-369.

3. Delrio AN, Marceddu S, Montella A, Gasparini G, Gulisano M. Structural organization of the menisci of the human knee: scanning electron microscopy study [in Italian]. Boll Della Soc Ital Biol Sper. 1992;68(6):359-364.

4. Fabbriciani C, Lucania L, Milano G, Schiavone Panni A, Evangelisti M. Meniscal allografts: cryopreservation vs deep-frozen technique. An experimental study in goats. Knee Surg Sports Traumatol Arthrosc. 1997;5(2):124-134.

5. Fideler BM, Vangsness CT, Lu B, Orlando C, Moore T. Gamma irradiation: effects on biomechanical properties of human bone-patellar tendon-bone allografts. Am J Sports Med. 1995;23(5):643-646.

6. Gelber PE, Gonzalez G, Lloreta JL, Reina F, Caceres E, Monllau JC. Freezing causes changes in the meniscus collagen net: a newultrastructural meniscus disarray scale. Knee Surg Sports Traumatol Arthrosc. 2008;16(4):353-359.

7. GelberPE, Gonzalez G, Torres R, Garcia Giralt N, Caceres E, Monllau JC. Cryopreservation does not alter the ultrastructure of the meniscus. Knee Surg Sports Traumatol Arthrosc. 2009;1 7(6):639-644.

8. Ghadially FN, Lalonde JM, Wedge JH. Ultrastructure of normal and torn menisci of the human kneejoint. JAnat. 1983;136(pt 4):773-791.

9. Giannini S, Buda R, Di Caprio F, et al. Effects of freezing on the biomechanical and structural properties of human posterior tibial tendons. Int Orthop. 2008;32(2):145-151.

10. HiguchiH, Kimura M, Shirakura K, Terauchi M, TakagishiK. Factors affecting long-term results after arthroscopic partial meniscectomy. Clin Orthop Relat Res. 2000;377:161-168.

11. Horsky I, Huraj E, Huraj E, Sklovsky A. Degenerative changes in the knee joint after meniscectomy [in Slovak]. Acta Chir Orthop Traumatol Cech. 1987;54(6):517-521.

12. Katsuragawa $Y$, SaitohK, Tanaka N, et al. Changes of human menisci in osteoarthritic knee joints. Osteoarthritis Cartilage. 2010;1 8(9):1133-1143. 
13. Kohn MD, Sassoon AA, Fernando ND. Classifications in brief: Kellgren-Lawrence classification of osteoarthritis. Clin Orthop Relat Res. 2016;474(8):1886.

14. Krüger-Franke M, Siebert CH, Kugler A, Trouillier HH, Rosemeyer B. Late results after arthroscopic partial medial meniscectomy. Knee Surg Sports Traumatol Arthrosc. 1999;7(2):81-84.

15. Lewis PB, Williams JM, Hallab N, Virdi A, Yanke A, Cole BJ. Multiple freeze-thaw cycled meniscal allograft tissue: a biomechanical, biochemical, and histologic analysis. J Orthop Res. 2008;26(1):49-55.

16. Pegg DE. Principles of cryopreservation. Methods Mol Biol. 2015;1257:3-19.

17. Vangsness CT, GarcialA, Mills CR, KainerMA, Roberts MR, Moore TM. Allograft transplantation in the knee: tissue regulation, procurement, processing, and sterilization. Am J SportsMed.2003;31(3):474-481 .
18. Verdonk PCM, Demurie A, Almqvist KF, Veys EM, Verbruggen G, Verdonk R. Transplantation of viable meniscal allograft: survivorship analysis and clinical outcome of one hundred cases. J Bone Joint Surg Am. 2005;87(4):71 5-724.

19. Verdonk PCM, Verstraete KL, Almqvist KF, et al. Meniscal allograft transplantation: long-term clinical results with radiological and magnetic resonance imaging correlations. Knee Surg Sports Traumatol Arthrosc. 2006;14(8):694-706.

20. Wallis MA, Griffin RL. A routine method for embedding animal tissues in Spurr resin for electron microscopy. J Clin Pathol. 1973;26(1):7778.

21. Wirth CJ, Peters G, Milachowski KA, Weismeier KG, Kohn D. Longterm results of meniscal allograft transplantation. Am J Sports Med. 2002;30(2):174-181.

For reprints and permission queries, please visit SAGE's Web site at http://www.sagepub.com/journalsPermissions.nav. 